\title{
Decoração e gênero: a construção de um fazer feminino
}

\section{Decoration and gender: the construction of a female doing}

\author{
ALVES, Aline Kedma Araujo; Mestranda do PPGAV - UFBA \\ alinekedma@outlook.com \\ FACTUM, Ana Beatriz Simon; Profa. Dra. do PPGAV - UFBA e UNEB \\ biasimon@gmail.com
}

\section{Resumo}

Este artigo pretende investigar os limiares entre decoração e gênero, discutindo o modo como as artes decorativas foram, historicamente, feminizadas no mundo artístico ocidental. Trata-se de uma revisão bibliográfica que discute a relação de gênero intrínseca à classificação das artes como menores e maiores, baseada principalmente na teoria de Giorgio Vasari. É possível afirmar que a arte decorativa, em virtude de seus atributos materiais e não somente da autoria, possua um "gênero"? Pode-se, a partir dessas conjecturas, depreender a decoração/design de interiores como um fazer feminino? Uma vez que a ideia da decoração foi construída na relação posta entre mulheres, o âmbito doméstico e as artes menores, a decoração se revela como um fazer feminino. A partir destas constatações e reflexões, espera-se contribuir para a história do design sob a perspectiva dos estudos de gênero e mais especificamente para a história do design de interiores.

Palavras Chave: arte; decoração; gênero.

\begin{abstract}
This article intends to investigate the thresholds between decoration and gender, discussing how the decorative arts were historically feminized in the Western artistic world. This is a bibliographical review that discusses the relation of gender intrinsic to the classification of the arts as minor and major, based mainly on the theory of Giorgio Vasari. Is it possible to affirm that the decorative art, by virtue of its material attributes, and not only of authorship, possesses a "genre"? Is it possible, from these conjectures, to grasp the decor / interior design as a female doing / genre technology? Since the idea of decoration has been built historically in the relationship between women, domestic scope and minor arts, the decoration reveals itself as a feminine doing. From these reflections, it is hoped to bring relevant contributions to the history of design from the perspective of gender studies and more specifically to the history of interior design.
\end{abstract}

Keywords: art, decoration, gender. 


\section{Introdução}

Este artigo é parte da pesquisa em desenvolvimento no mestrado do Programa de PósGraduação em Artes Visuais da Universidade Federal da Bahia-EBA/UFBA, na linha de Arte e Design: processos, teorias e história; e pretende discutir a feminização da decoração e artes decorativas através da classificação das artes maiores e menores postulada, principalmente, por Giorgio Vasari, crítico italiano da história da arte a partir do século XIV.

Trata-se de uma revisão bibliográfica que se apoia em teóricos da história da arte, sobretudo na obra de Vasari; nas abordagens feministas ao campo de estudo, como é o caso das teóricas Linda Nochlin e Griselda Pollock; nos estudos de gênero; e na perspectiva da cultura material para situar as inferências dos papeis sociais (BEAUVOIR, 1960) atribuídos às mulheres no exercício da decoração.

O campo do design carece de conteúdo sob a perspectiva dos estudos de gênero. É preciso considerar que esta é uma área de estudo em processo constante de sistematização de sua teoria e história, principalmente no Brasil. Desta forma, a relação entre os estudos de gênero e o design de interiores é ainda mais carente de estudos sistematizados. Este tema está longe de ser esgotado, embora já tenha tido algumas contribuições importantes ${ }^{1}$. Considera-se, essencial trazer para este estudo as classificações e categorias cunhadas ao longo da história da arte para entender as atuais problematizações no campo do design e cultura visual da arte.

Percebe-se que os objetos artísticos e simbólicos associados à feminilidade são aqueles que consubstanciam a separação entre o universo do trabalho e o universo doméstico e que, portanto, materializam justamente o que se esperava das práticas e funções "femininas". Principalmente as de salvaguardar o ambiente íntimo e familiar dos desvios e contaminações do mundo da rua, do trabalho, em suma, do universo público. Ou seja, a relação de gênero está presente em todo o contexto de categorização das artes e mais especificamente no da arte decorativa, de onde se faz a relação para a decoração e para o design de interiores.

Para Vicente (2012), todos os conceitos intrínsecos ao fazer artístico, como originalidade, genialidade e outros foram construídos ao lado de uma idealização e direcionamento de gênero específico: o masculino. Segundo a autora, "[...] a estes conceitos, poderíamos acrescentar aquele que estava implícito em todos eles - tão presente que nem precisava de ser nomeado -, o da masculinidade da criação artística" (VICENTE, 2012, p.22). Portanto, uma abordagem feminista da história da arte é necessária e urgente.

É válido ressaltar que o termo "gênero", utilizado aqui amplamente, se faz observando as noções dicotômicas e binárias de feminino e masculino/mulher e homem, porém, sem ignorar a complexidade em suas abrangentes e múltiplas manifestações (SCOTT, 1989).

Este artigo é composto por esta introdução, três itens e a conclusão. Nesta introdução explana-se como o artigo será abordado em questão de temática e metodologia. 0 desenvolvimento foi subdividido em três itens: o primeiro, intitulado "Artes maiores e menores", apresenta as categorias criadas ao longo da história para a arte e suas implicações; o segundo item intitulado "As artes femininas" explica quais categorias artísticas seriam consideradas femininas e quais são as alusões cunhadas por estes termos; o terceiro item "As artes decorativas, decoração

\footnotetext{
${ }^{1}$ Destaca-se como parte dessas contribuições CARVALHO (2008) e MALTA (2011).
} 
e relações de gênero" discute as artes decorativas e decoração, propriamente dita, imbricada nas relações de gênero. Encerra-se com a "Conclusão" onde apresenta-se as demonstrações e reflexões finais e aponta-se as contribuições deste estudo.

\section{Artes maiores e menores}

A distinção entre "artes maiores" e "menores" remonta à Antiguidade clássica, pela separação entre as atividades mentais e os trabalhos manuais. Os gregos distinguiam as artes superiores (que dizem respeito aos sentidos considerados superiores, visão e audição) das menores, de modo geral associadas aos ofícios práticos e ao artesanato. De forma parecida, a obra de Giorgio Vasari ${ }^{2}$, considerada de maior relevância para o estabelecimento dessas divisões dentro da história da arte, estabelece o artista como o indivíduo dotado de capacidades intelectuais específicas (ligadas ao desenho). Desse modo, a atividade artística é registrada no livro Le Vite de' piú eccellenti architetti, pittori, et scultori italiani, publicado em 1550, como fruto do trabalho reflexivo individual que elevaria intelectualmente o seu respectivo criador (SIMIONI, 2010, p.4). Neste livro, o autor apresenta diversos artistas florentinos (homens e mulheres) e divide a produção artística entre artes maiores e menores (VICENTE, 2012).

Segundo Vasari, as artes maiores seriam as de grande habilidade técnica baseadas no desenho: a pintura, a escultura e a arquitetura. E, portanto, consideradas intelectuais. O desenho a partir de então passou a ser compreendido como atividade "concebida no cérebro e executada pelas mãos, fruto, assim, de uma ação mental" (SIMIONI, 2010, p.4). A arte menor, por oposição, seria uma arte desprovida de técnica e intelecto, geralmente passada de pai para filho em famílias menos abastadas. Seria a arte da execução e não da criação. E por isso, considerada de talento inferior.

Além da obra mencionada, Vasari fundou na Itália em 1563 a primeira Academia de Desegno para formação de artistas, onde recebiam formação matemática e filosófica (científica e humanística), diferenciando definitivamente da visão de arte como ofício manual. Este modelo foi amplamente difundido por toda a Europa e segundo Darras (2006) "essa academia foi construída em oposição ao sistema de corporações, que administrava as carreiras de todos os artesãos e, principalmente, dos que faziam parte de pintores e gravadores de imagens."

Bernard Darras, esteta francês no campo da semiótica aplicada à cultura material e estudos culturais, faz uma reflexão acurada sobre o desenvolvimento da cultura visual, problematizando a história da arte como construção sob um ponto de vista privilegiado socialmente e por isso questionável. Para ele esta visão aristocrática "embora muito difundida esta versão da história ainda sofre de um viés retrospectivo provocado por um conceito de história conquistado pela tese de superioridade da arte". Segundo Darras, os "artesãos da imagem" foram invisibilizados com o passar do tempo. Profissionais do período contemporâneo ao de Vasari, trabalhavam nos estúdios e corporações e realizavam um trabalho manual - mas nem por isso apenas de reprodução - aliando teoria e prática na produção de imagens. E foram gradualmente ofuscados pelas Academias, mudando sua forma de transmitir o conhecimento, fragmentando sua práxis e em pequeno número (cerca de 8\%) compondo estas escolas que se espalhavam por toda a Europa (DARRAS, 2006, p.3).

Após a definição de Vasari, outros autores também propuseram relações e dicotomias na

\footnotetext{
2 Giorgio Vasari (1511-1574), pintor, arquiteto, pensador do Renascimento italiano florentino e fundador da primeira Academia de Desegno na Itália em 1563.
} 
classificação das artes como os já conhecidos termos: artes puras, artes aplicadas, artes liberais, artes mecânicas e belas-artes. Este último, conhecido também pelo termo em francês beaux-arts, estabelecido por volta do século XVIII, é aplicado às chamadas artes superiores de caráter nãoutilitário, opostas às artes aplicadas e às artes decorativas. Com a publicação da obra Les Beaux-Arts Réduits à un Même Principe, 1746, do filósofo francês Charles Batteaux, essa noção incorpora-se ao vocabulário da história e da crítica de arte. Na sua teoria, Batteaux defendia as artes plásticas, poesia, música, dança e literatura como imitações da beleza da natureza e por isso belas artes. Alguns anos mais tarde na Enciclopédia de Diderot (1713-1784) e D'Alembert (1717-1783), a arquitetura é incluída entre as belas-artes, em clara crítica ao que diz serem "imprecisões" de Batteaux (BEAUX-ARTS, 2018).

Outros teóricos e historiadores modernos questionaram em suas obras os limites entre as artes maiores, puras ou belas-artes e as consideradas como artes menores e/ou decorativas. Como é o caso de Giulio Carlo Argan, historiador da arte, que considera "uma distinção válida apenas para as culturas que a estabeleceram e nem sequer é resolutivo neste caso: existem obras de ourivesaria, esmaltes, tecidos, cerâmicas, etc. que, artisticamente, valem mais do que obras medíocres de arquitetura, pintura ou escultura" (ARGAN, FAGIOLLO, 1994, p. 14). Pelo pensamento de Argan (1994), a arte está ligada ao trabalho humano e consiste em uma simbiose entre o trabalho operacional e mental. Desta forma, não implica que a qualidade técnica de uma obra faça jus à fama da categoria a qual esteja inserida. Entretanto, observa-se que o reconhecimento da mesma se dá a partir da relação entre a categoria e autoria, como é comum nas artes menores consideradas como artes femininas, como se verá no próximo item.

\section{As artes femininas}

A categorização das artes como maiores e menores está relacionada à questão de gênero, uma vez que com a inserção do modelo vivo na pintura nas Academias de arte, as belas artes deixaram de ser recomendadas para mulheres. Deste modo, elas passaram a ser vetadas e encorajadas a produzirem artes menores, consideradas como tais: as miniaturas, as pinturas em porcelana, as pinturas decorativas, as aquarelas, entalhes em móveis, douramentos, marchetarias, peças de roupas, tapeçarias e bordados (SIMIONI, 2010, p.5).

Se por um lado as circunstâncias resultantes da educação que era direcionada às mulheres já dificultavam seu acesso às escolas de arte, por outro, este acesso foi vetado completamente com o pré-requisito de se trabalhar com modelos vivos nas Academias. O que favoreceu a associação das práticas artísticas consideradas adequadas para mulheres com as artes menores, "tapeçaria e o bordado, centrais durante a Idade Média, passaram, ao longo da Idade Moderna, a comportar duas cargas simbólicas negativas: a do trabalho "feminino", logo inferior, e a do trabalho manual, a cada dia mais desqualificado" (SIMIONI, 2010, p.3).

Assim, "a diferenciação entre 'artes maiores' e 'artes menores' (artes decorativas, produção industrial) também estava imbuída de uma diferenciação sexual" (VICENTE, 2012, p. 26). Esta diferença estava posta no século XIX de forma tal que essas atividades artísticas eram também conhecidas como trabalhos ou lavores femininos (Figura 1). Para serem consideradas femininas, além da autoria majoritariamente feminina, essas obras tinham uma relação próxima ao universo doméstico, território marcadamente feminino a partir da ideia de casa burguesa consistente na segunda metade do século XIX no Brasil (MALTA, 2011). 
Figura 1 - Artigo da Revista Feminina sobre Trabalhos Femininos: Almofada para sofá. fev. 1922

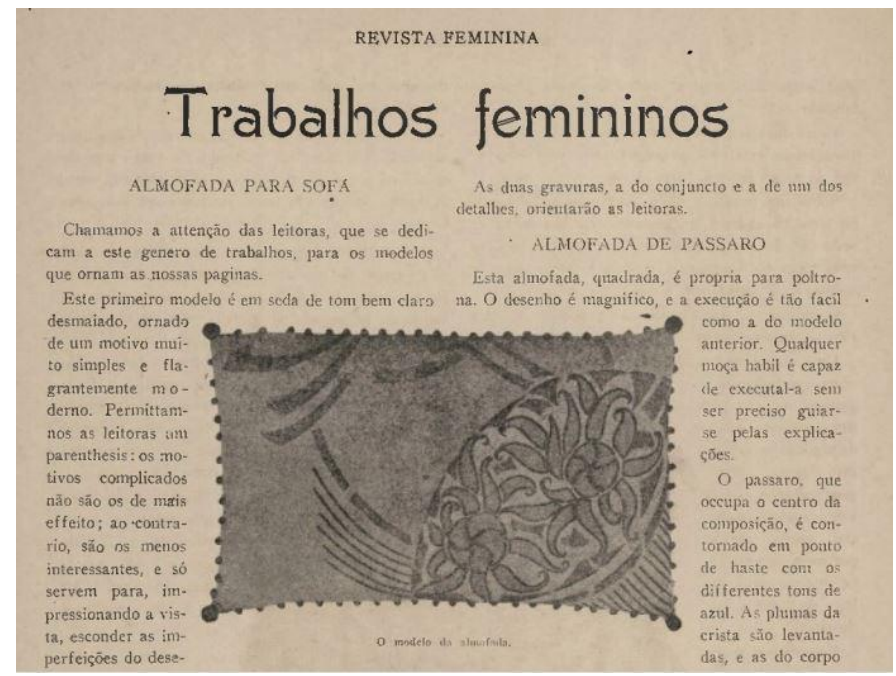

Fonte: http://www.arquivoestado.sp.gov.br/site/acervo/repositorio_digital/jornais_revistas

Consequentemente, as artistas mulheres eram consideradas incapazes de realizar outros trabalhos que não os do âmbito doméstico, ao passo que não eram impedidas de praticá-los por serem considerados artes menores, eram também desvalorizadas por se tratarem de lavores femininos. "Ou seja, quando a prática artística das mulheres não era excluída, tendia a ser inferiorizada" (VICENTE, 2012, p. 27).

A associação de algumas atividades têxteis - como a tecelagem, bordado e outras - como atividades femininas é relacionada por Simioni (2007) à diversos fatores que fortaleceram esta mentalidade.

Como por exemplo, ao livro chamado História geral da economia, publicado por Max Weber, sociólogo alemão em 1919, que diferenciou as profissões masculinas "como a medicina, na qual o trabalho teria um componente espiritual ou mágico, e os trabalhos femininos, como a tecelagem da seda, ou a produção têxtil para as indústrias domésticas, considerados formas puras de labor" (SIMIONI, 2007, p.95-96). Por estar relacionada à uma produção fabril as atividades têxteis foram esvaziadas da sua dimensão artística se contrapondo à ideia de produção artística masculina, de maneira mais livre, dissociada do chão de fábricas e associada às artes maiores.

Parte dessa associação se dá à realidade de que mesmo nas fábricas têxteis, que contavam com a mão de obra majoritariamente feminina, algumas funções eram restritas aos homens, principalmente os cargos de liderança, conforme deixa exposto Rago (1997):

[...] mesmo num ramo onde sua participação era enorme, como o têxtil, as alternativas de ocupação para os homens eram maiores. Enquanto eles estavam presentes em quase todas as atividades ocupadas pelas mulheres, como a costura de sacos ou nas maçaroqueiras, vários trabalhos eram interditados a elas, principalmente os de chefia. (RAGO, 1997, P.65)

É possível perceber a produção têxtil dissociada do fazer artístico propriamente dito e relacionada à figura feminina mesmo na Bauhaus, escola de vanguarda modernista alemã - iniciada também em 1919 na República de Weimar - onde se pretendia aliar as artes aplicadas às artes puras na ideia de alcançar artistas multifacetados. Em relação a questão de gênero, mesmo ao se tratar de uma escola revolucionária como a Bauhaus, não houve muitos avanços. Como pauta Simioni 
(2007):

Pode-se então compreender porque mesmo dentro dos circuitos modernistas prevalecesse certa ambiguidade na consideração das obras têxteis enquanto objetos "artísticos". $\mathrm{Na}$ Bauhaus, uma série de polarizações evidenciava as dimensões valorativas que contrapunham os campos. De um lado, figuravam os ateliês mais nobres - aqueles considerados industriais, como os de vidro e de metais, nos quais os produtos eram modernos, feitos por designers, que englobavam os alunos da instituição; de outro lado, estavam os ateliês marginalizados, cujo trabalho era mais manual e tradicional, como os de cerâmica e de tecelagem, tidos como mais artesanais e apropriados para as artistas do sexo feminino. Assim, a escola reiterava a tradição histórica da associação entre meios têxteis, mão de obra feminina e trabalho mais alienado do que propriamente inventivo. (SIMIONI, 2007, p.96)

Percebe-se que os princípios revolucionários alteraram muito pouco as relações entre os gêneros nesta instituição de ensino. E não por acaso, as professoras do sexo feminino eram direcionadas para estas disciplinas marginalizadas, encorajando de forma indireta (e não só) as estudantes mulheres a cursarem estes ateliês. Como reitera Simioni (2007):

Em 1920, o conselho reuniu-se, sugerindo uma separação, no momento da aceitação, sobretudo para o sexo feminino, cujo número está fortemente representado. Em poucos meses, estabeleceu-se que as mulheres seriam aceitas, preferencialmente, nos ateliês de cerâmica e de tecelagem; este último tornou-se praticamente um "nicho feminino" na escola." (SIMIONI, 2007, p.103)

Fora da Bauhaus, e apesar destes estigmas de amadorismo e artesanato, algumas artistas se dedicaram às artes têxteis como é o caso da suíça Alice Bailly; do artista italiano Giacomo Balla; da artista ucraniana Sonia Delaunay; e, ainda, a brasileira Regina Gomide Graz. Estes artistas foram pioneiros ao inserirem suas obras de tipo têxtil no campo artístico e conquistando notoriedade, mesmo sem questionar os critérios que definem a arte e seus mecanismos de exclusão no meio artístico (SIMIONI, 2010, p.8).

No âmbito brasileiro temos o caso de Regina Graz que exemplifica a divisão sexista do trabalho artístico pela visão modernista. Casada com Jhon Graz, arquiteto, Regina dividia as funções decorativas: ela fica responsável pelas artes têxteis, e ele pelo projeto decorativo na sua concepção. O que remete novamente a uma ideia de desenho e projeto defendida por Vasari como superior à arte decorativa em si. A linguagem artística da decoração era totalmente diferente dos objetos produzidos pelas donas de casa dos lares tradicionais burgueses ou demais artistas mulheres do período. O estilo arte déco, dialogava com as formas retas, futuristas do universo masculino, o que destacava absolutamente a obra de Regina Graz.

Sobre isto, Carvalho (2008) discute amplamente a atribuição de gênero para os objetos e estilos no sistema doméstico burguês na cidade de São Paulo durante o período de 1870-1920. Ela ressalta a associação destes objetos, por vezes de arte decorativa, às práticas e papeis sociais relacionados a homens e mulheres nestes tempos. "[...] tais objetos se tornam emblematicamente sexualizados. Tal imanência, no entanto, deve ser entendida como um resultado da prática social, cotidianamente reiterada pela prática social, momento em que se atribui o gênero aos objetos (CARVALHO, 2008, p. 44).

Assim como os objetos do cotidiano dentro dos interiores domésticos, a organização ou "anatomia dos interiores" (MALTA, 2011), a disposição do mobiliário, a ornamentação que se apresenta nos ambientes e objetos, bem como a rotina doméstica, reproduzem, de acordo com 
Carvalho (2008) ações centrípetas (masculinas) ou centrífugas (femininas) dentro de uma casa, de acordo com os aspectos sociais observados pela cultura material.

Por ações centrípetas/masculinas podemos ressaltar a presença dos óculos, canetas, binóculos, bustos escultóricos e móveis de escritório que têm identidades construídas como masculinas. Já a ação centrífuga/feminina seria uma ação mais difusa que "se faz sentir por toda a casa", visto que a responsabilidade e papel social da mulher seria relativo às questões da casa e família na maioria das vezes como único trabalho e distração (CARVALHO, 2008). Sobre estes aspectos da decoração enquanto "arte e ofício" femininos, tratar-se-á a seguir.

\section{Artes decorativas, decoração e relações de gênero}

A arte decorativa, por ter sido construída como uma arte feminina, como colocado à priori, é envolta de mais nuances das relações de gênero que as demais, principalmente por circunscrever a atmosfera do ambiente doméstico. Estes objetos artísticos são associados diretamente à feminilidade, principalmente por demarcar a separação entre o as esferas pública e privada. Além das ações centrípetas e centrífugas (CARVALHO, 2008) produzidas nos interiores dos ambientes, as obras de arte decorativa, por meio de seus objetos, materializam as expectativas dispensadas para cada gênero, mas demarca principalmente o feminino, que originou a sua categoria artística.

É sabido que uma das atribuições femininas é a de salvaguardar o ambiente do lar, como íntimo e familiar, dos desvios e contaminações do mundo externo: a rua, o trabalho, e em suma, o universo público. Desta forma, as expectativas criadas acerca da arte decorativa são as mais conservadoras possíveis na esfera doméstica, de maneira a estabilizar o ambiente transmitindo paz e bem-estar e não exatamente criando objetos artísticos de caráter subversivo.

Segundo Carvalho (2008) os objetos produzidos pela arte decorativa/feminina não seriam obras de arte, por não buscar nem subversão, nem criatividade, caraterísticas valoradas no meio artístico.

A arte feminina não trata, portanto, de obras de arte, mas de objetos capazes de proporcionar uma "sensação artística". A moderação é a regra básica que deverá conter os ímpetos de criatividade feminina. A arte doméstica não procura a originalidade e sim os efeitos. O objetivo é provocar os sentidos, porém não na busca de indagações, mas de paz. Nessa perspectiva, obedecer às normas da convenção parece ser o caminho mais seguro (CARVALHO, 2008, p.294).

Por "sensação artística" a autora traz o conceito de fruição visual, que seria segundo ela a primeira intenção da arte decorativa e da decoração como um todo. Ao contrário da arte como rompimento, a intenção seria então, produzir através da arte decorativa um efeito "neutralizador" das sensações humanas nos ambientes internos, "uma realidade instável que, em vez de gerar um impulso de mudança, acaba gerando um forte desejo pela vida contemplativa e auto referenciada" (CARVALHO, 2008, p.295). Este sentimento de fruição e contemplação confere à decoração um "fazer artístico" de caráter conservador do status quo.

Até a legitimidade da arte (decorativa) como tal, segundo Carvalho (2008) referenciando à Plumet (1907), é dada pela tensão feminino-masculino. Ou seja, uma peça de arte decorativa se destaca quando tem elementos originais que fogem da "condição feminina" do objeto, como uma exceção à regra, relacionando o marcador de gênero feminino como sinônimo da falta de originalidade e personalidade desta obra artística, como declara:

Os momentos de exceção são interpretados como resultado da força da personalidade do 
artista que consegue, com o brilho do pensamento, ultrapassar o objeto ao qual o talento costuma estar subjugado. Se a marca individual não floresce, o objeto decorativo é lançado na vala comum dos trabalhos manuais femininos (CARVALHO, 2008, p.294).

A decoração, propriamente dita, como arte feminina, segundo Carvalho (2008) está ligada intimamente à ideia da mulher como criadora e difusora da beleza nos lares para agradar, principalmente, ao homem. Reiterando assim, o papel social de mãe-esposa-dona de casa, tão aclamado e divulgado pelos periódicos leigos e científicos do início do século $\mathrm{XX}$, como se pode constatar na ilustração a esquerda da Figura 2.

Figura 2 - Propaganda ilustrada da pastilha Belloc: Para ser feliz. llustrando o padrão ideal de mulher da época. Revista A cigarra, abril de 1926.

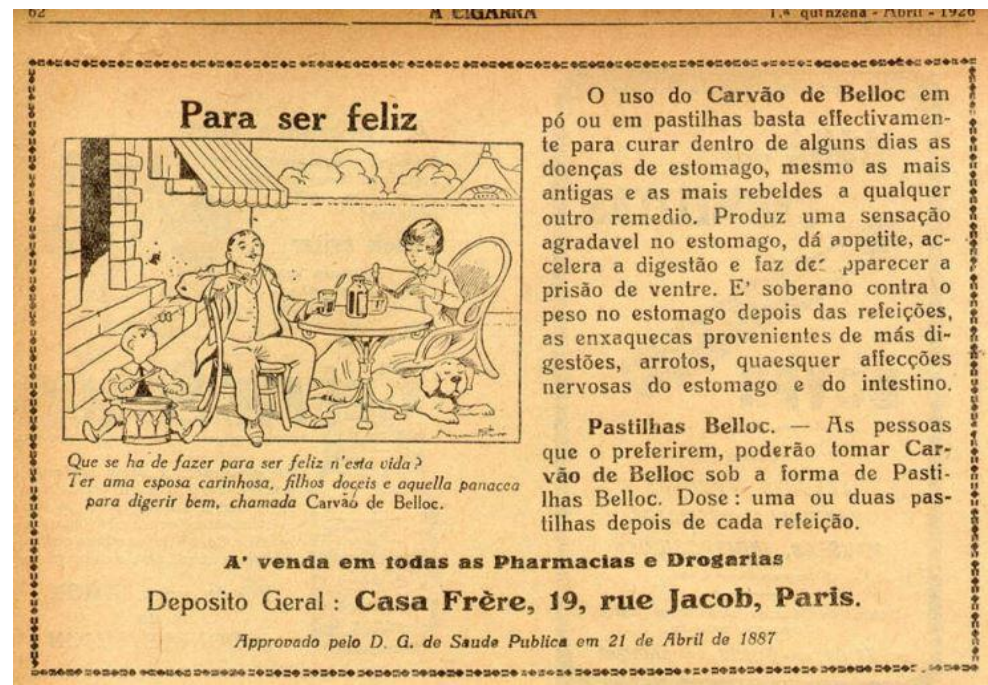

Fonte: www.arquivoestado.sp.gov.br/site/acervo/repositorio_digital/jornais_revistas

Conforme Carvalho (2008) a ideia de conforto na casa, através da decoração, está relacionada historicamente à felicidade, harmonia e ao gênero feminino:

[...] encontramos associados os três elementos constitutivos da ideia de conforto, e que ao longo deste capítulo, procuramos demonstrar como estão historicamente articulados: felicidade, harmonia e mulher. [...] A felicidade, que deve ser proporcionada ao homem pela mulher, consiste na produção do belo. A beleza é o resultado bem-sucedido de uma organização doméstica composta segundo as regras estéticas da harmonia, que se constituem antes de mais nada, pela combinação de cores e formas (CARVALHO, 2008, p.293).

Para atingir este ideal de agradar aqueles com quem convive através da sua conduta e da decoração da casa "é melhor que seus objetos não ultrapassem as fronteiras daquilo que é usualmente aceito e admirado por todos" (CARVALHO, 2008, p.294). Através do "toque feminino" a decoração como via de regra serviria ao status quo e manteria essa mesma mulher - representada simbolicamente pela arte feminina - neste lugar de subjugação destinado às mulheres.

Este lugar é acentuado quando se observa a constatação de um apagamento histórico das próprias mulheres artistas na arte decorativa. Apesar de ser considerada como uma arte feminina, a arte decorativa é exercida, muitas vezes, por homens sem perder o caráter feminino: 
decorativa não deixará de ser percebida como uma prática estreitamente relacionada com o perfil feminino. Por isso mesmo, fora do circuito doméstico, esse tipo de trabalho "artístico" será visto com desconfiança. (CARVALHO, 2008, p.294)

O mesmo acontece na decoração como prática de organização dos ambientes interiores. Estigmatizada como campo de domínio dos saberes femininos, o reconhecimento quase sempre se dá aos profissionais homens. Como é o caso de John Graz e Regina Gomide Graz, casal modernista que realizou em conjunto ambientações e decoração de ambientes, tendo os maiores créditos por tal trabalho o arquiteto John Graz, pelo caráter projetual conferido por esta atividade, e à Regina, ficaram os créditos da arte têxtil aplicada na decoração, vista como ornamentação (SIMIONI, 2010, p.8).

De acordo ainda com Vicente (2012), com a crescente profissionalização das artistas de arte decorativa foi cunhado um termo que generalizava "a categoria de 'pintora-amadora', ou seja, da mulher que praticava as artes, no espaço privado, sem ser artista" (VICENTE, 2012, p.26). Ainda que exercendo profissionalmente num círculo próximo ao seu convívio, estas mulheres eram vistas como amadoras e desqualificadas enquanto artistas-decoradoras, vivendo um duplo apagamento. Causado este, pela desvalorização da categoria como "menor" e feminina, e pela falta de reconhecimento de seus trabalhos enquanto mulher.

\section{Conclusão}

O objetivo deste artigo foi realizar uma revisão de literatura problematizando a relação de gênero intrínseca à classificação das artes como menores e maiores, buscando responder a questões como: a arte decorativa possui um "gênero"? A decoração/design de interiores é um fazer feminino?

Nos estudos realizados constata-se que as artes decorativas por vezes não são consideradas arte, por não conter a atmosfera transgressora e de quebra de paradigmas presentes em vários movimentos artísticos. Considerando, então, que é uma arte feminina e utilizada para manter o status quo, como falar da dimensão "verdadeiramente" artística destas peças? Seria necessário entender o lugar da mulher em vários períodos para traçar as conjecturas sobre este tipo de arte, a decorativa. Além de problematizar o exercício dela por homens ou o seu destaque neste tipo de arte.

Desta forma, é possível empreender que categorizar a arte como feminina foi uma maneira de mantê-la relacionada a decoração, circunscrevendo-a no lugar feminino, de onde não deveriam sair, limitando estes sujeitos, as mulheres, a continuar produzindo neste sentido objetos pseudoneutros.

Não é possível falar ainda sobre resistência neste lugar de subjugação dos indivíduos mulheres no campo da decoração e das artes decorativas. O modo como as artes decorativas foram historicamente feminizadas no mundo artístico ocidental praticamente impossibilitam o exercício de liberdade efetiva na sociedade atual. Mas o trabalho de provocar fissuras na superestrutura continua, até que todos os lugares sejam lugares, apenas, que se deseje estar, independente da condição de gênero, raça, sexo e classe. 


\section{Referências}

ARGAN, Giulio Carlo; FAGIOLO, Maurizio. Guia de História da Arte. São Paulo: Editora Estampa, 1994.

BEAUVOIR, Simone. O segundo Sexo: fatos e mitos. São Paulo: Difusão Europeia do Livro, 1960.

Beux-arts. In: Enciclopédia Itaú Cultural de Arte e Cultura Brasileiras, 2018. (http://enciclopedia.itaucultural.org.br/termo6177/beaux-arts)

CARVALHO, Vânia Carneiro de. Gênero e Artefato: O sistema doméstico na perspectiva da cultura material - São Paulo, 1870-1920. São Paulo, Edusp/Fapesp, 2008.

DARRAS, Bernard. Artists and Designers - Can the divide be overcome? In: Anais do VII Congresso Brasileiro de Pesquisa e Desenvolvimento em Design. Curitiba, 2006. p. 1-17.

MALTA, Marize. O olhar decorativo: ambientes domésticos em fins do século XIX no Rio de Janeiro. Rio de Janeiro: Mauad X, 2011. 248 p.

RAGO, Margareth. Do cabaré ao lar: A Utopia da cidade disciplinar. São Paulo: Paz e Terra, 1997. $213 \mathrm{p}$.

Regina Graz. In: Enciclopédia Itaú Cultural de Arte e Cultura Brasileiras, 2018. (http://enciclopedia.itaucultural.org.br/termo6177/regina-graz)

SIMIONI, Ana Paula Cavalcanti. Regina Gomide Graz: modernismo, arte têxtil e relações de gênero no Brasil. Revista do Instituto de Estudos Brasileiros, n. 45, p. 87-202, set. 2007.

SIMIONI, A. P. C. Bordado e transgressão: questões de gênero na arte de Rosana Paulino e Rosana Palazyan. IN: Proa - Revista de Antropologia e Arte. n. 02, p. 01-20, nov. 2010.

VICENTE, Filipa Lowndes. A página em branco. In: VICENTE, Filipa Lowndes. A arte sem história: Mulheres e cultura artística (séculos XVI-XX). 2. ed. Lisboa: Athena, 2012. 